artelogie

\section{Artelogie}

Recherche sur les arts, le patrimoine et la littérature de l'Amérique latine

$13 \mid 2019$

Violeta Parra: authenticité, primitivisme et processus d'exotisme chez les artistes latino-américains.

\title{
Geografías humanas y espacios del Chile moderno en las "Décimas" de Violeta Parra
}

\section{Patricia Vilches}

\section{(2) OpenEdition \\ 1 Journals}

\section{Edición electrónica}

URL: http://journals.openedition.org/artelogie/3098

DOI: 10.4000/artelogie.3098

ISSN: 2115-6395

Editor

Association ESCAL

Referencia electrónica

Patricia Vilches, « Geografías humanas y espacios del Chile moderno en las "Décimas" de Violeta Parra », Artelogie [En línea], 13 | 2019, Publicado el 07 enero 2019, consultado el 20 abril 2019. URL: http://journals.openedition.org/artelogie/3098 ; DOI : 10.4000/artelogie.3098

Este documento fue generado automáticamente el 20 abril 2019.

Association ESCAL 


\title{
Geografías humanas y espacios del Chile moderno en las "Décimas" de Violeta Parra
}

\author{
Patricia Vilches
}

1 Violeta Parra dejó un rico y multifacético legado artístico en donde se destaca la poesía, la recopilación folclórica, la pintura, la escultura, la cerámica y otros tipos de expresiones artísticas, lo que revela un espíritu infatigable. A este corpus se incorpora el compendio de multiplicidad creativa titulado Décimas. Autobiografía en versos, obra poética escrita por la autora alrededor de 1957 (MIRANDA, 2001: p. 3) o 1958 (MORALES, 2003: p. 54) y finalizada alrededor de 1959 (HERRERO, 2017: p. 706). La obra proyecta vicisitudes íntimas de la poeta, en narraciones que asemejan las técnicas interpretativas de sus canciones, "sin preocuparse de los atuendos, sin maquillarse y sin adoptar una pose exterior de figura 'folklórica' al uso oficial” (Ángel Parra en EPPLE, 2012: p.47). A la vez, la obra proporciona una perspectiva crítica sobre la sociedad en que vive, en donde se entretejen versos biográficos con versos que aluden a los problemas de la nación, como aquellos que claman por mejores derechos cívicos y de salud para los chilenos. Bajo esta óptica, este estudio abarca un análisis de las Décimas desde perspectivas que incorporan 1.) análisis del texto como ancla innovadora $y$ tradicional literaria; 2 .) geografía de vida íntima e historia nacional; 3.) reflexión y discurso que delinea espacios que prohíben, otros que narran sobre el cuerpo enfermo, además de aquellos que revelan aspectos de la masculinidad y la feminidad, presentes en la familia Parra.

2 Henri Lefebvre afirma que "la práctica espacial de una sociedad secreta el espacio de dicha sociedad" y que "lo propone y lo presupone" (1991: p. 38). ${ }^{i}$ Desde este enfoque, los versos de las Décimas posicionan y describen, en parte, el Chile de la niñez, juventud y etapa de adultez de la poeta, a la vez que denotan los crueles efectos de la modernidad en la sociedad chilena. Habiendo nacido en 1917 en San Fabián de Alico (alrededor de $68 \mathrm{~km}$. de Chillán, ciudad con la cual la poeta ha sido identificada), ${ }^{\text {ii }}$ Violeta tuvo una vida itinerante entre pueblo y ciudad, pero fue más bien en el ámbito urbano donde la artista puso en marcha estrategias artísticas y performativas, comprometiéndose con una 
especie de 'llamado' visceral hacia sus compatriotas, conociendo y haciendo conocer su nación. En efecto, Leonidas Morales concibe como eje en la obra de Violeta Parra un sentimiento de pérdida de lo tradicional, absorbido por una cultura urbana enajenada y desordenada (2003: pp. 58-59). Esto posibilita apreciar cómo las Décimas en sí se perfilan por espacios urbanos de conflicto (en donde también se inserta lo rural), haciendo que ambos ámbitos sean habitados por la 'narradora' de las Décimas (parte personaje, parte autora) y que en este estudio llevará nombres que incluyen 'voz poética', 'yo' lírico o, simplemente, 'la Violeta'. .iii $^{\prime}$

Publicadas póstumamente, las Décimas encarnan una conceptualización de totalidad en la obra de Violeta; poesía, arte visual, música e interpretación se compenetran entre sí, al igual que lo oral y lo escrito. Por eso, para la artista una canción "se 'escribe", haciendo que el "género de la oralidad" exhiba "cualidades de la escritura" (MIRANDA, 2013: p. 27). Además, las Décimas desarrollan un plano convergente en donde se conceptualizan reflexiones y digresiones que incorporan conceptos de muerte-vida, riqueza-pobreza y engaño-verdad, en donde el 'vil' progreso deja de lado a los sectores más vulnerables de la sociedad. La geografía de los versos recorre planos nacionales e internacionales, manifestando los logros y luchas de 'la Violeta' y de sus pares a un nivel que se identifica de forma paralela como íntimo y público; los desasosiegos de la propia autora se proyectan a nivel nacional, tipificando un mapa humano-geográfico plenamente parriano. Si se tiene en cuenta que los periódicos y las novelas del siglo XVIII proveen simultaneidad para la sociedad y representan la "comunidad imaginada" de la nación (ANDERSON, 2006: p. 25), las Décimas proporcionan episodios críticos en el desarrollo de la comunidad chilena.

El legado de la artista es resguardado por seguidores que provienen de un ámbito académico y por un público en general, con el propósito unánime de perpetuar la huella dejada por ella, diseminadora de una semilla artística que sigue cosechando, "reflejada en grupos musicales comprometidos con los procesos políticos e históricos del país" (VILCHES, 2004: p. 197). A Violeta se le considera como madre de la Nueva Canción Chilena, la guía que indicara el camino a los intérpretes que hicieron vibrar a las generaciones de los sesenta y tempranos setenta en Chile (MORRIS, 2014; GONZÁLEZ, OLSEN, y ROLLE, 2009; GONZÁLEZ, 2018); este hecho inserta toda la obra artística de Violeta en episodios claves nacionales, destacándose las Décimas en parte como narrativa de las motivaciones que iniciaron la lucha por la presidencia de Salvador Allende Gossens, 1970-1973. De hecho, la división nacional y dominio capitalista que se aprecia en la narración poética ayuda a explicar el 11 de septiembre de 1973, donde un sector de la población chilena apoyó tanto la intervención gubernamental estadounidense como la rebelión de las Fuerzas Armadas chilenas, lo que culminó en un golpe militar que truncó la presidencia de Allende. En el siglo XXI, como la figura mitificada de Allende (quien experimentara un 'nacimiento' al morir), Violeta Parra arrasa con los márgenes nacionales, causando la perplejidad de algunos en su nación.

5 La Lira Popular se evidencia en el siglo XIX en hojas de medio pliego que los poetas populares circulan "en espacios públicos de las zonas urbanas de Chile", procurando atraer la atención de la comunidad para alertar sobre las desigualdades de la sociedad (GARCÍA, 2013: p. 41). De este modo, mientras la oficialidad universaliza y jerarquiza la subjetividad 'oficialista' nacional, los poetas versean sobre crudas realidades del país, de talante humorístico y a veces satírico pero que retrata amarguras (MANNS, 2017: p. 97). iv Como ancestros de las Décimas, aquellos versos dejan en evidencia el arraigo del arte 
popular chileno en el espacio de protesta social en Chile, forjando una identidad nacional y sacando a luz "el propio desmedro social de sus autores" (GARCíA, 2013: p. 45). Descartados de la oficialidad, los poetas recorren el territorio, transportando su obra en metafóricas (y verdaderas) "viejas maletas" (MANNS, 2017: p. 95). Siguiendo la misma suerte, las Décimas no reciben la atención debida, ni siquiera por parte de la intelectualidad o los partidos políticos de izquierda del tiempo, si se considera que Violeta lee sus Décimas frente a un emperifollado auditorio y que presenta el texto para un concurso patrocinado por la municipalidad de Santiago, sin recibir resultado (SÁEZ, 2017: p. 338). Es decir, el texto no es valorado o comprendido por los sectores cercanos a la artista, señalando el reto que ofrece lo artístico popular a la ciudad letrada y militante. El afán de mantener el partido comunista a un nivel 'obrerista', y no intelectual, tampoco permite en ese entonces que se reconozca desde un inicio el valor de los versos de la poeta (HERRERO, 2017: pp. 709-710).

Después de la muerte de Violeta Parra la comunidad intelectual chilena se aboca desde un inicio a ensalzar su legado artístico, haciendo que las Décimas se publiquen en 1970. ${ }^{\mathrm{V}}$ At texto se le agregan versos de Pablo Neruda, Nicanor Parra y Pablo de Rokha; ${ }^{\text {vi }}$ sin embargo, los elogios de los poetas no provienen tanto desde una praxis analítica del texto poético mismo, sino que más bien desde una plataforma de veneración hacia la artista:

De cielo en cielo corre o nada o canta / la violeta terrestre ... Santa de greda pura! ... transformada, en pueblo verdadero (Neruda) (Escrito entre Isla Negra and Casablanca, 1970) (PARRA, 1976: pp. 11-13).

Porque tú no te compras ni te vendes / Porque hablas la lengua de la tierra / Viola chilensis (N. Parra) (PARRA, 1976: p. 17).

La gran placenta de la tierra la está pariendo ... Por eso es pueblo y dolor popular ... porque el pueblo es complejo, sencillo, tremendo e inmortal (De Rokha) (Escrito en París, 1964) (PARRA, 1976: p. 23).

7 Los versos de los vates convierten a Violeta en un símbolo nacional de 'chilenidad'; valorizan el legado del texto al mismo tiempo que dejan de lado un discurso crítico sobre la autobiografía, soslayando un análisis de la creación poética de una artista que enfrenta con rebeldía el diario vivir femenino en la modernidad. En cierto sentido, la propia poeta da pie a una interpretación de 'la Violeta del pueblo'. Paula Miranda analiza que los versos de las Décimas se inscriben en una afirmación artística de la poeta, quien se define inmersa "en la cultura popular campesina chilena, especialmente la relacionada con las cantoras chilenas" (2013: p. 23). Iraida H. López destaca que Violeta forja una imagen que la relaciona estrechamente con el pueblo y utiliza las Décimas como el vehículo a través del cual podemos apreciar "el cultivo de dicha imagen" (2010: p. 133). Tomando en cuenta las palabras de Neruda, se desprende que la artista encarna el prototipo de una campesina que emerge de la Madre Tierra. Las estrofas se deleitan en desarrollar una Violeta Parra mítica, poeta trágica de siglo XX chileno. Neruda, Nicanor Parra y de Rokha exteriorizan así la percepción nacional de Violeta como portavoz de un pueblo o como el 'pueblo' mismo, enajenado en la urbe, representando la música y las artes a la vez que las prácticas populares, como los velorios de angelitos o las curas para el empacho (de las que nos habla doña Rosa Lorca).

8 La conceptualización de las Décimas asemeja los parámetros musicales instaurados por Violeta en su proyecto de recopilación. Miranda indica que las Décimas son escritas en un momento de fruición en la afanosa recopilación musical de la artista, lo que la lleva a componer temas originales y experimentales, asimilando la tradición y creando composiciones como "El gavilán” y "Hace falta un guerrillero" (2013: p. 70). Nancy Morris 
(2014) y Juan Pablo González (2018) analizan los altos estándares y, también, la originalidad presente en la creación musical de la chillaneja, combinando en sus canciones música culta con música popular. De la misma manera, Morales expone que la elaboración de las Décimas conduce a una síntesis de una entera tradición que emana de versos de corte europeas y de aquellos establecidos en narraciones "a petición", de confesor a monja (2003: p. 53), en combinación con el folclor y lo popular, desde "las canciones de los borrachos" al canto a lo divino (2003: p. 76). En definitiva, el poemario invoca un peregrinaje simbólico y físico de una exploradora que intersecta y acarrea una amalgama de vivencias, como la inmigración hacia Santiago de muchos chilenos, convertidos por el 'yo' lírico en musas de la barriada (VILCHES, 2008: p. 66).

9 El estatus de Violeta como ícono nacional ha provocado que su legado también haya sido apoderado por sectores conservadores que eligen cuidadosamente lo que se permiten admirar de la artista. ${ }^{\text {vii }}$ De esta forma, durante la segunda propuesta presidencial del candidato de derecha Sebastián Piñera en 2017, se eligió 'Gracias a la vida' de Violeta Parra como una de las canciones que simbolizara su plataforma para volver al poder, hecho que inflamó los medios sociales. Por el contrario, durante las protestas estudiantiles del 2011, cuando Piñera estaba en su primera presidencia, Violeta Parra y sus hijos artísticos, donde sobresalen Víctor Jara y los descendientes de la familia Parra en general, sirvieron como símbolo contestatario y fuerza de acción para una juventud que se sentía 'dejada de lado' de los propósitos gubernamentales del gobierno de Piñera. No obstante, al mismo tiempo que Violeta es universal, su obra poética ensalza y atestigua las vicisitudes de una mujer chilena que debe contender con un deseo irreprimible de conocer, saber, amar, (entre otras inquietudes) y que no duda en proclamar las injusticias sociales de su época. Digamos, en consecuencia, que en las Décimas podemos evidenciar raíces latentes de desazón en la artista, las que la llevan a tomar una decisión irrevocable de suicidarse en la Carpa de La Reina el 5 de febrero de 1967, alrededor de diez años después de concluir su poemario. Como aducen sus biógrafos, Violeta se sentía abandonada e incomprendida, hecho que a posteriori convierte a las Décimas en memoria y testimonio, lo que Miranda ha denominado un "ejercicio antropológico de autoconocimiento y construcción del sujeto" (2013; 23), y que revela una autobiografía de lo íntimo en que sobresalen los desafíos de la artista a nivel privado y nacional. Sin exagerar, entonces, las Décimas narran la espacialidad de la historia del diario vivir chileno vía el 'yo' lírico o 'la Violeta' de Violeta Parra.

\section{Innovación y tradición literaria en las Décimas}

11 El desdoblamiento de Violeta como autora-narradora se inserta en la literatura tradicional a la vez que en aquella folclórico-popular, formando un poemario innovador que se escabulle de la tradición literaria y que inevitablemente la sigue. La estructura del texto abarca alrededor de ochenta y tres poemas de diez estrofas octosilábicas cada una, siguiendo generalmente la rima abba-ac-cdde, "como comentario de glosa o cuarteta inicial” (AGOSÍN y DÖLZ BLACKBURN, 1988: p. 25). Los versos hilvanan una larga tradición escritural enraizada en los siglos XVI y XVII del Siglo de Oro español, una cultura transportada por colonizadores y emigrantes que llegaron al Nuevo Mundo y que fue filtrada consecutivamente por la poesía popular, abarcando lo urbano y lo rural, produciendo lo que Miranda designa como "un discurso extraño" de tradición poética 
popular y afirmación social (2001: p. 7). Este modus operandi se adhiere, por una parte, a la tradición poética del siglo XVI, reproducida en la estrofa 'espinela', que lleva el nombre del poeta Vicente Espinel, evidenciada en su obra Diversas Rimas (1591) (AGOSín y DÖLZ BLACKBURN, 1988: p. 25). Desde otro ángulo, la poeta traza una estudiada oralidad en donde el 'yo' lírico se compenetra con una comunidad campesina que la escucha, ambos ajenos a la sofisticación de la gran urbe. Los versos, entonces, innovan por el hecho de que materializan simultáneamente alta cultura y cultura popular, Siglo de Oro chilenizado y poesía rural marginalizada, un método poético-juglar transmitido por generaciones en Chile y que fuera redescubierto por Violeta en su segunda etapa artística, cuando decidió no continuar siendo Violeta de Mayo:

$\mathrm{Pa}^{\prime}$ cantar de un improviso / se requiere buen talento, / memoria y entendimiento, / fuerza de gallo castizo. / Cual vendaval de granizos / han de florear los vocablos, / se ha de asombrar hast' el diablo / con muchas bellas razones, / como en las conversaciones / entre San Peiro y San Pablo.

También, señores oyentes, / se necesita estrumento, / muchísimos elementos / y compañero 'locuente; / ha de ser buen contendiente, / conoce'or de l'historia. / Quisiera tener memoria / pa' entablar un desafío, / pero no me da el sentío / pa' finalizar con gloria (Parra, 1976: p. 27).

Violeta recrea el cantar de un pueblo inmerso comunitariamente en quehaceres religiosos, agrícolas y musicales, reelaborando y transformando patrones que entrelazan la transmisión oral con la escrita, posicionada enclíticamente en el espacio de inmigración hacia la gran urbe. Como indica Juan Armando Epple, la artista se opone a un folclor envasado que transmite un "nacionalismo ideológico" que idealiza el "antiguo poder agrícola" como representante y base de la nación (1994). Escribiendo sus versos a posteriori, la poeta emplea recursos retóricos de sus recopilaciones folclóricas, los cuales hacen referencia a "las canciones populares, a punto de desaparecer de la memoria de los viejos campesinos" (SÁEZ, 2017: p. 144), al hilvanar versos con el lenguaje del campo para rememorar, por ejemplo, su asombro al indicar que su hermano Nicanor Parra la alienta a versear:

Fue grande sorpresa mía / cuando me dijo: Violeta, / ya que conocís la treta / de la vers'á popular, / princípiame a relatar / tus penurias 'a lo pueta' (PARRA, 1976: p. 29).

Los versos aluden a la tradición juglaresca en donde se inserta la paya; estos saltan de la página para reproducir un performance de lo que la poeta ha compuesto en un papel. Ericka Verba analiza el aspecto performativo de Violeta al examinar, por una parte, cómo la artista se representa al iniciar contacto con el Musée des Arts Décoratifs del Louvre, lo que culmina en la exhibición de sus arpilleras y artes plásticas en 1964; por un lado, aduce Verba, la propia narración de Violeta exalta su ingenuidad al encontrarse 'cara a cara' con el Louvre mientras que por otro, algunos escritos atestiguan un gran nivel de sofisticación por parte de la artista al establecer contacto con los parisinos (2013: p. 270). Al respecto, López delinea que Violeta narra a través de formulaciones poéticas que no se relacionan con códigos urbanos, con el afán de distanciarse de la poesía culta; López observa que sin glosario (el cual se agrega para la primera edición), parte de las Décimas no puede ser fácilmente captada por los lectores, lo cual conlleva la idea de que la publicación tiene en mira lectores que provienen de sectores urbanos (2010: p. 136; p. 140). Por consiguiente, su peregrinaje de recopilación señaliza para Violeta un serio compromiso con la 'verosimilitud performativa' de lo que presenta y cómo ella se representa, deshaciéndose de todo lo que ella percibe como artificial, lo cual exude una irreprimible añoranza por una pérdida de la unidad nacional, de "un destino compartido" (MORALES, 2003: p. 58), 
característica creada por la modernidad. Siguiendo rutas inmersas en el folclore 'escondido' de Chile, el viaje de aprendizaje de la artista sobre la música, la literatura y las artes visuales supone, entonces, un deseo de compartir su zozobra por los avatares de la modernidad, haciendo que su público, ya sea rural o sofisticado, experimente junto a ella "nostalgia por un pasado y lugar idealizados" (VERBA, 2013: p. 271).

Epple comenta sobre "el sentido social de los parámetros estéticos" de Violeta, quien no duda en combinar la tecnología del tiempo con su carrera artística; en su etapa prerecopilación folclórica, por ejemplo, la artista "se apropia, vía radiotelefonía, de la aventura sentimental del bolero, la ranchera, la tonada o la canción popular española" (1994). En el caso de las Décimas, Miranda hace notar que la artista subvierte los métodos para hacer circular su trabajo creativo, utilizando sin vacilar el disco para dar a conocer sus versos, traspasándolos de sus raíces poéticas-folclóricas y afiliándolos con lo urbano, lo masivo y lo popular (2001: p. 14). De la misma forma, utilizando la retórica de alta cultura y cultura popular almacenada en décimas, la artista reproduce algo innovador, un despedazamiento simbólico expresado en la proclamación del 'yo' lírico desde la perspectiva de 'pueta' y música del pueblo, lo que también incluye un ejercicio escritural de una canción que no se canta pero que se lee:

Y pa' cantar a porfía / habrá que ser toca'ora, / arrogante la cantora / para seguir melodía, / garantizar alegría / mientras dure'l contrapunto, / formar un bello conjunto / responder con gran destreza. / Yo veo que mi cabeza / no es capaz par'este asunto (PARRA, 1976: p. 28).

La voz poética nos mantiene 'en remojo' como lectores, seducidos por su autenticidad y conscientes a la vez de que los versos siguen una tradición clásica literaria, meticulosamente moldeados por un desdoblamiento, al estilo de textos de la cultura del oeste, como Dante Alighieri y su Divina Comedia (1321). Dante es peregrino-protagonista y, al mismo tiempo, Dante es autor, responsable de calibrar meticulosamente quién merece quedar en el Infierno, el Purgatorio o el Paraíso. En ese sentido, la raison d'être de las Décimas denota una voz lírica que expresa asombro, tentativa, duda, y resignación al determinar cómo llevar a cabo su labor poética mientras que la pluma se mueve sólida e incuestionablemente por el papel. Esta dualidad reproduce una amalgama de vida profesional y privada, emergiendo esta en una representación privada-pública que refleja los desafíos de la modernidad. Dante reflexiona sobre los hechos y conflictos de su vida en su viaje de exiliado hacia el norte, a ciudades como Ravena o Verona, vivencias que de algún modo se transmiten en La Divina Comedia en la interacción del 'Dante' peregrino con diversas tipologías humanas, santos o pecadores. Como el 'Dante' del texto, 'la Violeta' acusa y describe los abusos de unos cuantos (arruinar la vida de pequeñas vidas dándoles alcohol; permanecer indiferente ante la violación de una mujer; no rescatar a un pobre hombre borracho de matones que lo asaltan; negar ayudar a un compatriota en embajadas chilenas en el extranjero, entre otros). Así, los versos retratan a 'la Violeta' en relación a quehaceres humanos en su nación y lejos de ella, en lugares nunca antes vistos, tratando de procurarse un honesto vivir para continuar promoviendo su conocimiento artístico:

Viví clandestinamente / con tres chilenos gentiles, / lavándoles calcetines / cuatro días justamente: ... / voy de bolich'en boliche / para pegar el afiche / del nombre de mi país; / me abre su puerta París / como una mina'e caliche (PARRA, 1976: 207). Quijano, quien después de explorar y viajar por los recovecos recónditos de su biblioteca se desdobla en don Quijote, un individuo que expresa un rompimiento y una 
conceptualización binaria de su propio cuerpo. Como una moderna representación de don Quijote, 'la Violeta' de las Décimas no cesa de luchar por sus sueños y por lo que considera justo, atreviéndose a "confiar en su propia fuerza para forjarse un destino" (AGOSín y DÖLZ BLACKBURN, 1988: p. 24). En su intento de abarcar la vasta comunidad chilena, en donde se encuentra "el mejor libro de folklore que se haya escrito" (MANNS, 2017: p. 110), la artista alude en sus versos a un despedazamiento de su ser, al 'cuerpo desmembrado', parte del repertorio del 'canto a lo poeta', como lo es el 'apocalipsis' y 'el mundo al revés' (MIRANDA, 2013: p. 31); este concepto también se atribuye a la tradición del 'cuerpo repartido', perteneciente al folclor de San Fabián de Alico (HERRERO, 2017: p. 749-750). Significativamente, desde un binomio literatura 'clásica' y poesía popular, la voz poética se desdobla al utilizar métodos 'burgueses' y 'del pueblo' para indicar la otredad. Con una intranquilidad que nunca la abandona, Violeta "se despedaza y desintegra" por los confines recónditos de Chile, despojándose de su cuerpo de otrora para adentrarse en un nuevo cuerpo, o ser, al estilo de Lazarillo de Tormes o Rebecca Sharp (VILCHES, 2008: p. 66-67):

Un ojo dejé en Los Lagos / por un descuido casual, / el otro quedó en Parral / en un boliche de tragos. / Recuerdo que mucho estrago / de niña vio el alma mía; / miserias y alevosías / anudan mis pensamientos. / Entre las aguas y el viento / me pierdo en la lejanía. / Mi brazo derecho en Buin / quedó, señores oyentes, / el otro por San Vicente / quedó, no sé con qué fin...

Se m'enredó en San Rosendo / un pie al cruzar una esquina; / el otro en la Quiriquina / se me hunde mares adentro...

Mis nervios dejo en Granero, / la sangr' en San Sebastián, / y en la ciudad de Chillán / la calma me bajó a cero. / Mi riñonada en Cabrero / destruye una caminata, / y en una calle de Itata / se me rompió el estrumento ... Desembarcando en Riñihue / se vio la Violeta Parra, / sin cuerdas en la guitarra, / sin hojas en el colihue. / Una bandá' de chirigües / le vino a dar un concierto; / con su hermanito Roberto / y Cochepe forman un trío / que cant' a l'orilla 'el río / y en el vaivén de los puertos (Parra, 1976: 159-160).

17 La vida escritural de las Décimas es impulsada por la poeta siguiendo un mapa geográfico en donde deja parte de sí. El cuerpo de Violeta se enreda, se hunde, se pierde, y lo demás, mientras desembarca, se baja de un tren, o desciende de un avión en diferentes partes de Chile para alimentar su sed de proteger y difundir un legado. Por un lado, la fragmentación de 'la Violeta' equivale al contrario de la plenitud, dando a entender "los desplazamientos y los sinsabores de la modernidad" (LÓPEZ, 2010: p. 142). Por otro, pese al enorme desafío que conlleva su misión de recopilación, el largo e intranquilo recorrer de la poeta por distintos recovecos de Chile la catapultan a un deseo de renovación en su vida (de cambio de caparazón, muda de piel) a través del re-conocimiento de un folclor que la está esperando en las zonas rurales y urbanas marginadas de su nación.

Su escritura la posiciona como una innovadora en investigación folclórica. Al respecto, en sus Cantos folklóricos chilenos (publicado por Zig-Zag en 1959 y por Nascimiento en 1979), Violeta narra sobre las dificultades y el cuidado de conseguir la confianza de sus informantes, provenientes "de zonas entonces campesinas aledañas a Santiago, como Barrancas, Puente Alto y Pirque" (GARCíA, 2013: p. 62), haciendo resaltar la generosidad y cortesía entre entrevistados y entrevistadora. Acompañada en este empeño por Luis Gastón Soublette, Sergio Larraín y Sergio Bravo, la artista y sus informantes quedan enmarcados en fotografías del texto, con una narración que explica la alegría y el dolor de ser cantor: "Las lágrimas de don Guillermo se deshacían en los 'tuntuneos' de los entorchados de la guitarra" (PARRA, 1979: p. 9). En Violeta se fue a los cielos (2011), un film 
basado en el libro homónimo de Ángel Parra (2006) y dirigido por Andrés Wood, los guionistas utilizan buena parte de Cantos folklóricos en las escenas de Violeta con sus informantes, proveyendo el film de autenticidad y retratando la afabilidad con que la artista se dirige hacia sus informantes y la seriedad con la que ella emprende su carrera como recopiladora. Estas escenas también sirven para recalcar el tono desafiante de Violeta al dirigirse a un público conservador e indiferente. Al respecto, Marisol García enfatiza el alto valor que la artista adjudica a su material de estudio, la cultura popular de Chile: "Quiere explicarla casi didácticamente, y transmite la idea de que sus viajes y sus proyectos están inscritos en ese mismo esfuerzo de difusión" (2016: p. 13). Por ese afán de enseñar y difundir, la artista desaparece por largos periodos de su casa para recorrer el país en toda su extensión, recopilando letras y música, dejando una parte de sí y añadiendo a pulso, a través de caminatas, aventuras y encuentros, a su preciado repertorio artístico, lo que equivale a una verdadera empresa quijotesca.

\section{Espacios de historia íntima y nacional en las Décimas.}

La poesía contestataria de Violeta enfatiza el binomio urbano-agrícola y poder económico existente ya en la colonia. En el capítulo 'Campo y Ciudad' de su Historia general de Chile, Alfredo Jocelyn-Holt alude a la costumbre de los miembros de la oligarquía criolla colonial de mantener un hábitat urbano y otro rural. La geografía urbana es el punto en donde los criollos se mantienen al tanto sobre las maniobras de los peninsulares y, más que nada, es el lugar donde se preparan para intentar soslayar las demandas impuestas por la rebuscada burocracia peninsular; por eso, los parámetros de las áreas rurales sirven más bien de "repliegue" que de "atrincheramiento", sobre todo cuando el poder de una familia se encuentra ya consolidado en la ciudad (JOCELYN-HOLT, 2014: p. 431). En las Décimas, las piernas, la voz, el cuerpo de la voz poética se convierten en conector entre lo rural y lo urbano, juntando estas áreas con su música y aportando una herencia a los que han emigrado a la ciudad (VILCHES, 2008: p. 62). Para la oligarquía colonial, de la cual descienden los 'contrincantes' del pueblo y que se visualizan en las Décimas (a menudo como 'los ricos' o 'los políticos'), la ciudad establece parámetros necesarios para mantener el poder: "La ciudad exterioriza, visibiliza y representa mejor que la hacienda las distintas apuestas y cartas tendidas sobre la mesa de juego" (JOCELYN-HOLT, 2014: p. 431).

20 La actividad artística de Violeta en suelo chileno repercute en canciones grabadas en suelo extranjero (como es el caso de Francia y Suiza) para hacer despertar a la nación sobre la devastación e injusticia social en Chile y Latinoamérica en general. Las Décimas dan vida a una narración 'patriota' que lucha contra la enajenación y desculturización de la nación, con habitantes prendados de música extranjerizante que proviene de mercados euro-norteamericanos, postulando que se debe rescatar una moribunda 'chilenidad'. Los versos hablan de una nítida separación entre los que poseen la tierra y los que deben procurarse un techo trabajándola. Los primeros son perfilados como una mezcla de individuos dotados de poder oligárquico y seducidos por el capitalismo, prestos a intercambiar un concepto idealista de nación por uno comercial y mercantilista; los segundos son bosquejados como súbditos obligados a lidiar con un despotismo secular. En el texto, 'la Violeta' llega a la gran ciudad en tren y pese al miedo de la gran máquina se entrevé en la narradora el propósito de luchar para salir adelante en la urbe; recuenta las dificultades que confronta en la ciudad aunque no pierde las esperanzas de que las cosas 
se arreglen y de que "un día este pobre pueblo teng'a una feliz mudanza" (PARRA, 1976: p. 170). En Durante La Reconquista (1897), Alberto Blest Gana provee las semillas que se desarrollan en las Décimas, indicando cómo asuntos pecuniarios priman en la conceptualización del territorio chileno. Bajo este prisma, la narración de Durante La Reconquista alude a la lucha territorial que se centraliza en el texto de Violeta Parra. La novela de Blest Gana narra sobre la breve pero humillante reconquista de España del territorio chileno, 1814-1817 (etapa concluida cien años antes del nacimiento de Violeta).

Basándose en relatos de historiadores clásicos chilenos, Blest Gana describe cómo la ciudad de Santiago 'es secuestrada' por los peninsulares en su regreso a Chile, territorio considerado suficientemente vulnerable por los españoles; en la recuperación del territorio se aprecia la diferencia entre los aguerridos patriotas y los criollos realistas; son todos criollos, descendientes de aquellos colonizadores que habían llegado al Nuevo Mundo, pero estos hijos de europeos nacidos en suelo americano dificultan la percepción de 'nacionalidad' por parte de los europeos (ANDERSON, 2006: p. 60). Ellos mismos experimentan desasosiego con sus raíces, haciendo que en la novela algunos se identifiquen con Chile y otros con España. En las Décimas, los descendientes de los criollos ya han arreglado sus diferencias y representan la oligarquía terrateniente, la que mantiene el control de la sociedad; ellos son ricos y 'perfumados', con el derecho de habitar espacios prohibidos para los demás, como bellas casas y jardines vistosos sembrados de flores, que inclusive en la muerte acompañan en fastuosos funerales. Para los desposeídos, eso sí, no existe un espacio "porque justicia en la vi’a no existe p'a los rotosos" (PARRA, 1976: p. 175). Así, para uno y otro, la noción de que ambos grupos comparten la nación parece ser un concepto ajeno.

Para Violeta, ciertamente, "son los propios chilenos" que le quitan la posibilidad de un buen vivir a muchos, como ella indica en su canción "Arauco tiene una pena"; los políticos $y$ adinerados no dudan en vender el territorio para sacar ganancia. Por eso, sin omitir que Blest Gana representa la voz de una elite intelectual, la narración de su novela 'saca los trapitos al sol', dejando en claro que la reconquista del Reino de Chile es bendecida por una gran parte del territorio, incluyendo familias de bien e inquilinos, quienes rinden pleitesía y están siempre al servicio de los colonizadores. El autor chileno retrata la ciudad de Santiago como el escenario predilecto para los criollos realistas, quienes se exhiben y deshacen en halagos hacia quienes imponen un anacrónico Viejo Orden; al contrario, los verdaderos patriotas se refugian en sus campos, rehusando ser vistos en la ciudad, mientras que complotan cómo erradicar a los peninsulares de lo que ellos ya consideran como su propia nación. Junto con inmortalizar la figura de Manuel Rodríguez, Blest Gana da vida a personajes que reflejan la voz del pueblo, asemejándose a aquellos que se retratan en las Décimas. De hecho, en Canciones reencontradas en París (1971, Dicap), Violeta Parra encomia en "Un río de sangre" a Rodríguez y Luis Emilio Recabarren.

En Durante la Reconquista, los héroes se distinguen de los cobardes, los realistas valientes de los siniestros ejecutores, los patriotas de los vendidos, los materialistas de los idealistas, y así sucesivamente, subrayando la valentía de Rodríguez y enfatizando que muy pocos pueden llegar a la altura de su patriotismo (VILCHES, 2017: p. 230). En episodios memorables, Rodríguez (desinteresado en bienes materiales y enamorado de su patria), por voluntad propia se mete en la boca del lobo, presto a ser apresado o muerto por un 'godo' (peninsular). Al dar vida a personajes del pueblo, por lo tanto, Blest Gana narra la historia de la Reconquista e Independencia final de Chile desde otras voces, desde una diversa perspectiva, un aspecto que une a esta novela con las Décimas. Robles y 
Cámara, personajes de Durante La Reconquista, son dos individuos que emulan el arrojo de Rodríguez; los dos están dispuestos a sacrificar la vida para salvar a la nación de la opresión española (2017: p. 244). Al referirse al Desastre de Rancagua, un episodio crítico en la historia de Chile, la narración le da la responsabilidad a Robles, un hombre del pueblo:

Todita la noche nos llevamos en vela, pita que pita, para no dormirse y que se nos entrasen los godos (BLEST GANA, 2010: p. 124).

En Mi nueva canción chilena (2016), Ángel Parra 'encapsula' desde el siglo XXI una percepción enraizada en el artista y sus pares durante la época rebelde de los sesenta, en que los portadores de la Nueva Canción narran 'otra' historia sobre el nacimiento de Chile, una que no acepta la versión oficial de polvorientos libros de historia sobre los acontecimientos que dan lugar a la independencia chilena:

¿Somos hoy realmente independientes? ¿Quiénes se separaron de la Corona española? La aristocracia gobernante. No fue el pueblo; el pueblo estuvo al margen, como siempre. Políticos, oportunistas, ejércitos de la época, en guerra o en paz con los mapuche, según conveniencia de unos o de otros (PARRA, 2016).

Siguiendo aquella línea histórica, Violeta Parra narra sobre los altibajos del Chile del siglo $\mathrm{XX}$, señalando cómo la nación encuentra entre sus propios súbditos enemigos irreconciliables. Esto se convierte en una característica prevalente del gobierno de Allende y podría decirse que cuando 'se da vuelta la tortilla', como espera la voz poética de las Décimas, los opositores de Allende se apresuran a volver a ponerla en su sitio, a como dé lugar: se involucra El Mercurio, la CIA, la ITT, la administración de Nixon, entre otras organizaciones, para asegurar que 'la tortilla' vuelva al lugar que le corresponde, donde la tierra está con unos pocos. La voz poética, por cierto, al presentar a su abuelo materno Ricardo Sandoval, señaliza la intrincada relación que Sandoval mantiene con el dueño de los terrenos donde habita la familia:

Mi abuelo por parte 'e maire / era inquilino mayor, / capataz y cuidador / poco menos que del aire; / el rico con su donaire, / lo tenía obliga'o / caballerizo monta'o / de viñatero y rondín, / podador en el jardín / y hortalicero forza'o. / Todo esto, señores míos, / por un cuartito de tierra / y una galleta más perra / que llevaba a sus críos; / algunos reales, ¡Dios mío!, / pa' alimentar quince humanos, / sin mencionar los hermanos/ que se apegaban al pial (PARRA, 1976: p. 35).

En una reciente biografía sobre la artista, Herrero dedica tiempo a desmitificar la pobreza de la familia de Violeta, aduciendo que Sandoval era en realidad un hombre semiacomodado "que arrendaba paños de tierra para el cultivo de uvas y producción de vino" (2017: p. 12). Sin embargo, la narración de las Décimas deja en claro que la voz lírica se siente parte del pueblo sacrificado por el derecho a la tierra, retratando geografías de conflicto y adversidad. En cuanto a su abuelo paterno, ejercía la profesión de "agente paralegal que se desempeñaba en los tribunales" (HERRERO, 2017: p. 9), una descripción que encuentra eco en las características proporcionadas por la voz poética: "él no era un ñato petizo" (PARRA, 1976: p. 33). Fuera de sus actividades como agente paralegal, su abuelo paterno participa en eventos monumentales de la historia chilena, específicamente en la Guerra del Pacífico (1879-1883), en donde Chile se enfrentó con Perú y Bolivia por causas que aludían al "dinero y recursos materiales" (SEPÚLVEDA, 2014: p. 476):

José Calixto su nombre, / fue bastante respeta'o, / amistoso y muy letra' o, / su talento les asombre; / más le aumente su renombre / al decir muy en breve, / no más entre marte' y jueves / procura mostrar su honor, / defendiendo el tricolor / el año setentainueve (PARRA, 1976: p. 33). 
La Guerra del Pacífico ha dejado una huella indeleble en el imaginario de las tres naciones involucradas. Hasta la actualidad, problemas limítrofes y culturales han mantenido a estos países en una sempiterna alerta, prestos a alzar la voz ante cualquier amenaza. En al menos dos de sus arpilleras, Violeta Parra dejó inmortalizado uno de los episodios históricos más ensalzados de la historia nacional: el Combate Naval de Iquique, interpretando el salto al abordaje del capitán Arturo Prats desde la corbeta Esmeralda, y que lo llevara a una segura muerte al abordar el monitor Huáscar, en la actualidad convertido en un barco-museo anclado en Talcahuano. Desde esta perspectiva, por lo tanto, el mar es eje y mira de las tres naciones. Aludiendo a los intereses materiales impuestos en el conflicto que consumió a Chile, Alfredo Sepúlveda aduce que "En la guerra, por lo tanto, el país que controlara el mar ganaba el territorio, y Bolivia carecía de una armada" (2014: p. 494). Por su parte, después de una estadía en Bolivia, en años cercanos a su muerte y cuando intenta como sea reconectar con el suizo Gilbert FavreRun Run-, Violeta llega de vuelta a Santiago dejando en claro que se adhiere a los clamores de la nación boliviana por acceder al mar.

\section{Espacios de la modernidad en Chile}

Las transformaciones de la sociedad chilena en el siglo XX se evidencian en el peregrinaje vertiginoso de la propia familia Parra, viajeros del sur al centro de la urbe, y de vuelta al sur. Se ha indicado al respecto que con su autobiografía la artista retoma un "lenguaje de la infancia", el cual conlleva cultura popular-folclórica (MORALES, 2003: p. 74). De forma zigzagueante, entonces, las Décimas rememoran en parte la época de niñez de la artista, cuando con sus hermanos 'la Violeta' aprende sobre diversos aspectos del diario vivir, como la grandeza de la naturaleza, el rasgueo de la guitarra, el sonido de la máquina de coser y las visitas a parientes; asimila también los altibajos de la vida, refiriéndose a eventos familiares trágicos y a etapas socio-económicas difíciles, los que la llevan a tomar la decisión de salir de su entorno en plena adolescencia. De esta manera, observando, detallando y declamando, la voz poética de las Décimas desdibuja y alude a espacios que prohíben y separan:

Les cuento que salió un día / mi maire, cosa más rara, / apure señora Clara, / le dijo su compañía. / Contentas y en armonía / patrona y arrendataria, / partieron como canarias, / l'echaron llave a la puerta, / pero se les quedó abierta / la del jardín con las dalias.

En ese huerto se apila / el piño de cabros sueltos: ... / se pierden en las hortensias, jazmines de preferencias / perfuman su manantial /

...

son para todos las flores, / los montes, los arreboles. / ¿Por qué el pudiente se olvida?

Si el sol pudiera guardarlo, / lo hicieran de buena gana; / de nada, tarde y mañana / quisieran acapararlo, /

De rabia esconden las flores / los meten en calabozos, / privando al pobre rotoso / de sus radiantes colores (PARRA, 1976: pp. 61-63).

Lefebvre se refiere al tipo de separación espacial al que se alude en las Décimas: "El espacio de una habitación, un dormitorio, una casa o un jardín en cierto sentido puede estar separado del espacio social por barreras y paredes, por todos los signos de la propiedad privada, y aún así permanecer fundamentalmente como parte integrante de ese espacio" (1991: p. 87). El espacio del jardín de 'la Totito', amiga de Clara Sandoval (madre de 
Violeta), se mantiene cerrado para los niños Parra. Las estrofas reelaboran el topos del locus amoenus, intersectando lo clásico con lo popular y haciendo que la voz poética de las Décimas haga referencias a una expulsión por transgresión a las leyes del paraíso (MORALES, 2003: pp. 58-59). Los versos simbolizan parámetros jerárquicos sobre quienes se benefician de la belleza de la naturaleza, la que se ofrece en su totalidad solo a los que tienen acceso a ese jardín. Al encontrarse cara a cara con las flores, 'la Violeta' piensa que está "soñando despierta" (PARRA, 1976: p. 62), encontrando un paraíso donde puede brincar y ser feliz, por unos pocos momentos, en un espacio anteriormente vedado. Como indica Lefebvre, aunque tenga barreras, el jardín forma parte fundamental de la espacialidad de la casa, dividido por un mero 'click' cuando se le echa llave a la puerta; al olvidar ponerle cerrojo, la patrona permite que 'la Violeta' y sus hermanos puedan conocer lo que ellos habían apenas percibido "por un hoyito" de la puerta (PARRA, 1976: p. 62). Abarcando dos segmentos de décimas, la narración deja en claro que el descuido de 'la Totito' recae en el castigo de los niños, quienes pagan por la transgresión del espacio prohibido.

Distintos tipos de enfermedades ocupan un lugar preponderante en las Décimas, en donde 'la Violeta' informa a los lectores de que hay un 'antes' y un 'después' en la percepción de sí misma. Habiendo emigrado a Santiago, Clara Sandoval urge a su marido Nicanor a seguirla; por esta razón, en 1919 Nicanor viaja con toda su prole en busca de mejor vida, formando parte de miles de chilenos que viajaban a Santiago desde el sur o el norte, estos últimos traicionados por la fiebre del salitre. Herrero (2017: pp. 33-34) y Fernando Sáez (2017: pp. 37-38) concuerdan que la primera elección presidencial de Arturo Alessandri Palma crea las condiciones para que Nicanor sea nominado profesor de Estado en el regimiento militar de Lautaro. A guisa de comparación, el relato del afortunado viaje de la familia Parra a Lautaro se relaciona con una intrincable enfermedad del cuerpo de 'la Violeta', en donde la narración establece un preludio sobre las enfermedades infantiles sufridas por la niña, proponiendo un planteamiento físico-estético de la faz de 'la Violeta', maltratada por la fatalidad del diario vivir y, por ende, transformada de niña bonita a fea:

Dice mi mamá que fui / su guagua más donosita / pero la suerte maldita / no lo quiso consentir; / empezó a hacerme sufrir / primero, con la alfombrilla, / después la fiebre amarilla, me convirtió en orejón. / Otra vez el sarampión, / el pasmo y la culebrilla (PARRA, 1976: p. 43).

31 La memoria del impacto sufrido por las enfermedades infantiles conlleva un reconocimiento por parte del 'yo' lírico de una triste visión, mientras el tren avanza por el campo, de "las humildes cabañas de los pobres" (PARRA, 1976: p. 45). Tal como una enfermedad contagiosa, la pobreza del pueblo brota por los poros del territorio chileno. En ese fatídico viaje, Violeta se contagia de la viruela y pasa de ser una niña revoltosa a una niña consumida por los estragos de la enfermedad:

Contra su pecho, mi mama / me defendía furiosa, / como una joya preciosa ... / Su tibia fald'en mi cama / era muy grande consuelo. / La veo con sus desvelos, / humedeciendo mis labios; / la fiebre me daba agravios, / la sed me quita el resuello.

En este estado tan cruel / termina la deligencia. / Salimos de la presencia / fatal del maldito tren.

...

Cayeron grandes y chicos / con la terribl'epidemia / más grande que la leucemia; / murieron pobres y ricos. / Al hoyo, un tal Federico; / al saco, Juan Pimentel / y dos qu'estaban con él; unos tales Pérez Caro / que visitaron Lautaro, / jamás pudieron volver (PARRA, 1976: pp. 47-48). 
El padecimiento de Violeta Parra se proyecta a nivel nacional, donde ella es una víctima más de una epidemia de viruela que brota desde norte a sur del país, causando estragos en la población, sobre todo en los menores, debido al hacinamiento y las malas condiciones higiénicas que acompañaban los viajes hacia y desde Santiago (SÁEZ, 2017: pp. 39-40). La preponderancia de la viruela, transportada por los europeos durante la Conquista del Nuevo Mundo y con efecto mortífero para las culturas indígenas (y que queda marcada en el cuerpo de Violeta Parra), se reproduce en las Décimas como la enfermedad de 'la Violeta' y del Estado chileno. De hecho, esta enfermedad forma parte de las primeras décadas de Chile como nación, haciendo que el control y prevención del contagio de la viruela adquiera connotaciones políticas, unos abogando por intervención gubernamental $\mathrm{y}$ otros miedosos de aquel mismo clamor (SATER, 2003: pp. 513-514). Entonces, el contagio de 'la Violeta' representa un momento privado y público puesto que demuestra la vulnerabilidad de los espacios públicos para un gran sector de la población chilena. Es más, el horror que representa la posibilidad de contagio de una enfermedad convierte al enfermo en un verdadero zombi, en un ente amenazante para "el ambiente inmediato ya que su cuerpo está marcado por la promesa de extender su novedad" (GUERRERO y BOUZAGLO, 2009: p. 17). En el caso de Violeta, una alta fiebre e hinchazón del cuerpo confirma la enfermedad y hace sospechar a los demás pasajeros que la familia Parra está marcada; para no llamar la atención, sus padres cubren a la niña con mantas y tratan de calmar las tercianas, pero no pueden disimular las señales del cuerpo de la pequeña, haciendo que los pasajeros permanezcan "alertados por los murmullos de quienes habían visto las indisimulables manchas rojas en el rostro de la niña" (SÁEZ, 2017: p. 40). La madre de 'la Violeta' lucha contra la opresión de la viruela (y de las miradas aterrorizadas), deseando sanar a su hija, pero el cuerpecito de la inocente manda todas las señales y alarmas, confirmando que ya victimizado, el cuerpo adquiere el poder de vulnerar: "El contagiado se vuelve contagioso; la enfermedad, a la vez, enferma" (GUERRERO y BOUZAGLO, 2009: p. 17).

Un espacio de conflicto particular de la modernidad y presente en las Décimas concierne el rol del género en la sociedad chilena del tiempo. El propio padre de la artista se ve tremendamente afectado (y por ende la familia Parra) por los estragos causados por mercados internacionales, cambios gubernamentales, y la percepción que el padre posee de su masculinidad. En el film Violeta se fue a los cielos, Nicanor padre se percibe desde un ángulo 'irresistible' dado a que es atractivo, culto, artístico, a la vez que representa un 'proyecto' de hombre que no ha madurado y que desea ser 'salvado' y 'enderezado' por el buen camino. Interpretado por el actor Cristián Quevedo, Nicanor es un espíritu libre y vulnerable, incapaz de lidiar con los reveses que le da la vida, estrellando y despedazando una guitarra como gesto premonitorio de su propio trágico desenlace; como se transmite en las Décimas, Nicanor disfruta exhibiendo su talento musical, emborrachándose y tocando para quien le escuche, pero también parece resentir ese mismo genio artístico que lo lleva paulatinamente a una autodegradación. Siendo observado por la pequeña Violeta y sus hermanos, el padre se va apagando paulatinamente. Efectivamente, en el texto Violeta se fue a los cielos Ángel Parra describe a su abuelo materno con los parámetros trágico-románticos de un hombre 'bello pero dañado':

Mi abuelo cesante, deprimido o eufórico, enfiestado de manera permanente, hijos con hambre, igual, miseria. El trago, las trasnochadas, la tuberculosis y finalmente la muerte para el músico y poeta (PARRA, 2006). 

dramático ante el diario vivir. Nicanor es talento puro y reacciona con la guitarra y el alcohol tanto en momentos de felicidad como en aquellos que causan dolor y penuria. Representando a un prototípico hombre que arruina a su familia por causas del alcohol, el padre de 'la Violeta' en un momento de atolondrada gallardía no vacila en causar el mayor daño, firmando un papel en donde intercambia su casa por el derecho de ingerir más alcohol (PARRA, 1976: p. 113). Como estocada final, el padre es víctima de las medidas autocráticas de los presidentes fuertes que caracterizan y controlan la vida política de Chile en las tempranas décadas del siglo XX:

No tiene la culpa el chancho / sino quien le da el afrecho. / Hoy el instante aprovecho / para tomar mi revancho. / Del árbol salió este gancho / pa' repetirlo tan fuerte, / que si mi taita en la muerte / procura encontrar reposo, / fue por aquel fastidioso / Ibáñez, el presidente.

Es mucha su desventura, / lo vieran con su dolor, / declaro qu'el dictador / lo convirtió a la locura ... / se mueren las esperanzas, / no hay más posible venganza / que hablarlo a los cuatro vientos (PARRA, 1976: p. 115).

Carlos Ibañez del Campo, Presidente de Chile entre 1927 y 1931 y luego entre 1952 y 1958, ejerce su mandato con dureza y astucia, estableciéndose como candidato único y de facto primer dictador del siglo XX chileno (SEPÚLVEDA, 2014: p. 711). Como militar, toma medidas que favorecen considerablemente a las Fuerzas Armadas chilenas; ya como Vicepresidente determina que diferentes fuerzas policiacas suban de categoría para formar Carabineros de Chile, por ejemplo. Por otro lado, las medidas del militar afectan al personal civil que trabaja para el Ejército, como es el caso del padre de Violeta, decretando que los civiles no pueden continuar trabajando para dicha institución (SÁEZ, 2017: p. 46).

Violeta Parra misma pone en relieve las difíciles decisiones que debe tomar una artista que también es madre. Sin tener formación tradicional como artista, al decidir seguir una carrera de folclorista, Violeta debe luchar para adjudicarse un puesto en los jerárquicos salones de la música académica. Ángel Parra se refiere a las muchas veces que acompaña a su madre a la Universidad de Chile, a la Facultad de Música de dicha institución, con la esperanza de que la apoyen en su quijotesco esfuerzo de recopilación:

Cuántas veces esperamos dos, tres horas que un burócrata la recibiera, para decirle por toda respuesta que volviera en quince días. No es por rencor, pero hay que decirlo. Todo lo que realizó con amor por su pueblo, lo hizo con los organismos oficiales en contra (PARRA, 2006).

En la autobiografía, el suelo extranjero brinda el apoyo que la artista no recibe en su nación, un respaldo que se distingue por el alto precio que debe pagar 'la Violeta' al narrar sobre la desazón de haber aceptado una especie de pacto faustiano al decidir salir de Chile y dejar a su hija, Rosita Clara. Nacida en septiembre de 1954, la pequeña queda al cuidado de otros en Santiago, entre ellos de su hijo Ángel de once años:

Dejo botá' mi Nación, / mis crías y mi consorte; / ya tengo mi pasaporte, / m'está esperando el avión. / Penetrando en l'estación / un seremil de personas / me ruedan como corona / al verme sumida en llanto, / porque era mucho el quebranto / al partir para Polonia.

De nueve meses yo dejo / mi Rosa Clara en la cuna. / 'Com' esta maire, ninguna' / dice el marío perplejo. / Voy repartiendo consejo / llorando cual Maudalena, / y al son que corto cadena / le solicito a Jesús / que me oscurezca la luz / si esto no vale la pena (PARRA, 1976: p. 184). 
Epple destaca "el temple contestatario" de la artista presente en las decisiones de cómo vive su carrera y su trabajosa vida, en donde se destaca una "inclaudicable impronta personal como una postura feminista 'avant la lettre”' (1994). Sáez resume lo que muchos sostienen sobre la decisión de Violeta de salir en gira artística y de no haber vuelto a Chile al recibir la nefasta noticia de la muerte de su hijita. Ante la dolorosa y absoluta certeza de la muerte de Rosita Clara, tiene sentido y lógica que la artista no rompa sus planes, y que resuma y se concentre únicamente en su gira artística por Europa (2017: p. 228). Según Ángel Parra, la muerte de la pequeña fue "Unos de los grandes dolores de mi madre, nunca pudo superarlo" (PARRA, 2006). De forma fatídica, también, la muerte de Rosita Clara acentúa la relación vida-muerte que se desarrolla en la carrera artística de la poeta chilena: "la relación vida-muerte es de tal espesura e intensidad que su escritura y existencia se convierten en una celebración de la vida y una apropiación de la muerte" (ALONSO, 2011: p. 12). De hecho, las Décimas participan de esta conceptualización vidamuerte, no solo a través de versos por muerte, sino que también por el diario vivir que conlleva lo bueno y lo malo, lo apreciado y lo despreciado, un yin-yang presente en la totalidad de su vida que la dirige a crear y concluir, como reflexiona Nieves Alonso, que Violeta debe dar "Gracias a la vida... y darse la muerte: vacío y plenitud; silencio y sonido" (2011: p. 13).

\section{Mas van pasando los años}

En las Décimas Chile se entrevé en tenaz contienda con los avatares de la época moderna y los retazos de un pasado colonial, desde una espacialidad tensionada por la atmósfera de la época: una oligarquía que se aferra al control y un pueblo que despierta a los conflictos sociales y falsedades de la modernidad y de autoridades totalitarias. Llegamos a conocer su vida a través de versos que revelan una historia de marginalización y despotismo en Chile: "El código es un deshecho / de puntos muy singulares; / en contra del que no sabe / va la sentencia derecho" (PARRA, 1976: p. 178). Violeta narradora establece lo doloroso del oficio de compilador: "ando de arriba p'abajo desentierrando folklor. No sabís cuánto dolor, miseria y padecimiento me dan los versos qu'encuentro" (PARRA, 1976: p. 29). Inclusive en sus últimas entrevistas desde su Carpa de La Reina, Violeta Parra no deja de denunciar lo dificultoso que todo ha sido para ella y pide que la vaya a ver el público puesto que lo que ella propone no es "para que disfruten las sillas nomás" (GARCÍA, 2013: p. 225). Ya sabemos el resto. El espacio autoral de Violeta se asegura así a través de una narrativa urbana-manierista pionera en donde la autora compone versos 'rurales' sobre una vida itinerante por Chile y el mundo, al mismo tiempo que protesta en contra de la injusticia social (VILCHES, 2008: p. 62).

El texto implica reflexión y discurso que delinea espacios disputados, solidarios, prohibidos, compartidos, jerarquizados, sufridos, esperanzados, etc. Las Décimas subrayan la energía de una artista que impone la seriedad sobre el oficio de cantor. La trayectoria itinerante de Violeta, "limpiando tumbas y arreglando floreros en el cementerio o bien barriendo, lavando platos y sirviendo comidas" (SÁEZ, 2017: p. 54), cantando en las calles, actuando en los circos, caminando por zonas marginales para salvar letras de folclor de un seguro olvido, y demás, demuestran la tensión entre lo viejo y lo nuevo, y el empeño de la artista de salvar lo que desbarata la sociedad:

Mas van pasando los años, / las cosas son muy distintas: / lo que fue vino, hoy es tinta, ... / lo que fue cierto, hoy engaño. / Todo es penuria y quebranto, / de las 
leyes de hoy me espanto, / lo paso muy confundida, / y es grande torpeza mida /

buscar alivio en mi canto (PARRA, 1976: p. 39).

41 políticos de la mecanización y la deshumanización del capitalismo. La autora, artista musical y visual chilena escribe del mismo modo que recopila, utilizando métodos sui generis que extrañan en sus tiempos pero que fascinan a nivel nacional e internacional en el siglo XXI. A través de una vida itinerante e intranquila la poeta comunica sus experiencias en el milieu del diario vivir y los conflictos de la modernidad. El Chile contemporáneo, literal y metafóricamente, le rinde honor a su nombre en espacios urbanos y rurales con calles, estatuas, entre otros honores, y en la magnitud de representaciones, en donde se incluyen conciertos, escritos, grafiti, marchas y exposiciones, los que denotan su presencia en la nación, sobre todo ahora que existe un museo que lleva su nombre en Santiago. Las Décimas explican el monumental proyecto de la artista, desde poemas que aluden a los paisajes de su Chillán natal (centro-sur) de Chile y otros que se basan en su vida y trabajo en barrios y boliches modestos de Santiago, utilizando métodos tradicionales y populares, los cuales unen el pasado con el presente. En palabras de Ángel Parra, Violeta es "la mujer contemporánea que utiliza esa tradición para cantarle a su tiempo histórico" (EPPLE, 2012: p. 50). El texto poetiza los conflictos y vicisitudes de un pueblo que lidia en su diario vivir con una modernidad deshumanizadora que deja enormes secuelas y que explican las luchas sociales (entre ellas la larga candidatura de Allende y su breve paso en La Moneda) en un Chile del siglo XX.

\section{BIBLIOGRAFÍA}

AGOSÍN Marjorie, y DÖLZ BLACKBURN Inés (1988). Violeta Parra, santa de pura greda: Un estudio de su obra poética. Santiago, Chile, Planeta.

ALONSO Nieves (2011), “Soberanía sobre la muerte: El caso Violeta Parra.” Atenea 504: 11-39.

ANDERSON Benedict (2006), Imagined Communities: Reflections on the origins and spread of nationalism . Verso editions, New York. Documento electrónico.

BLEST GANA Alberto (2010), Durante la Reconquista: Novela histórica. Editado por Iván Jaksic y Juan Durán Luzio. Santiago, Chile, Editorial Universitaria.

DUARTE RIASCOS Jerónimo (2018), “La Violeta: Making the Transparent Opaque in Violeta Parra's Work.” In Mapping Violeta Parra's Cultural Landscapes, ed. Patricia Vilches, 43-56. New York, Palgrave Pivot.

EPPLE Juan Armando (1994). "Violeta Parra: Una memoria poético-musical”.

Archivo Chile. http://www.archivochile.com/Cultura_Arte_Educacion/vp/s/vpsobre0066.pdf.

EPPLE Juan Armando (2012). Entre mar y cordillera: Conversaciones sobre poesía, Violeta Parra y la nueva canción chilena. Concepción, Chile, Ediciones LAR, Literatura Americana Reunida. 
HERRERO Víctor (2017), Después de vivir un siglo: Una Biografía de Violeta Parra. Lumen, Documento electrónico.

GARCíA Marisol (2013), Canción Valiente. 1960-1989. Tres décadas de canto social y político en Chile. Santiago, Chile, Ediciones B Chile. Documento electrónico.

GARCíA Marisol (2016), Violeta Parra en sus palabras. Santiago, Chile, Catalonia, Periodismo UDP. Documento electrónico.

GONZÁLEZ Juan Pablo (2018), “Creator or Words and Songs.” In Mapping Violeta Parra's Cultural Landscapes, ed. Patricia Vilches, 75-88. New York, Palgrave Pivot.

GONZÁLEZ Juan Pablo, Óscar OHLSEN, y Claudio ROLLE (2009), Historia social de la música popular en Chile, 1950-1970. Santiago, Ediciones Universidad Católica de Chile.

GUERRERO, Javier, y Nathalie BOUZAGLO (2009), Excesos del cuerpo: Ficciones de contagio y enfermedad en América Latina. Buenos Aires, Eterna Cadencia.

JOCELYN-HOLT LETELIER Alfredo (2014), Historia general de Chile. Vol. 3, Editorial Sudamericana. Documento electrónico.

LEFEBVRE Henri (1991), The Production of space. Translated by Donald Nicholson Smith. Oxford, UK, Blackwell.

LÓPEZ Iraida H (2010), “Al filo de la modernidad: las décimas autobiográficas de violeta parra como literatura." Anales de literatura chilena 13: 131-150.

MANNS Patricio (2017), Violeta Parra: La guitarra indócil. Santiago, Chile, Penguin Random House. Documento electrónico.

MIRANDA Paula (2001), Las Décimas de Violeta Parra: autobiografía y uso de la tradición discursiva. Tesis de Magíster en literatura hispanoamericana y chilena, Universidad de Chile, Santiago. Disponible: http://www.cybertesis.cl/tesis/uchile/2001/miranda_p/html/indexframes.html.

MIRANDA Paula (2013), La poesía de Violeta Parra. Santiago, Chile, Cuarto Propio.

MORALES Leonidas (2003), Violeta Parra: La última canción. Santiago, Chile, Cuarto Propio.

MORRIS Nancy (2014), "New Song in Chile: Half a Century of Musical Activism." In The Militant Song Movement in Latin America: Chile, Uruguay, and Argentina, ed. Pablo Vila, 19-44. Lanham, Maryland, Lexington Books.

PARRA Ángel (2006), Violeta se fue a los cielos. Santiago, Chile, Catalonia. Documento electrónico.

PARRA Ángel (2016), Mi nueva canción chilena: Al pueblo lo que es del pueblo. Santiago, Chile, Catalonia. Documento Electrónico.

PARRA Isabel (2015), El libro mayor de Violeta Parra: Un relato biográfico y testimonial. $4^{\text {th }}$ ed. Santiago, Chile, Chabe producciones.

PARRA Violeta (1979). Cantos folklóricos chilenos. Santiago, Chile, Editorial Nascimento.

PARRA Violeta (1976), Décimas: autobiografia en versos. Introducidas por Pablo Neruda, Nicanor Parra y Pablo de Rokha. Barcelona, Pomaire.

SÁEZ Fernando (2017), La vida intranquila: Biografía esencial de Violeta Parra. Santiago, Chile, Planeta. Documento electrónico.

SATER William F (2003), “The Politics of Public Health: Smallpox in Chile.” Journal of Latin American Studies 35.3: 513-543. doi: http://www.jstor.org/stable/3875310. 
SEPÚLVEDA Alfredo (2014), Breve historia de Chile. Santiago, Chile, Sudamericana. Documento electrónico.

VERBA Ericka K. (2013), “To Paris and Back: Violeta Parra's Transnational Performance of Authenticity. The Americas 70.” No. 2: 269-302. doi: https://doi.org/10.1353/tam.2013.0091.

VILCHES Patricia (2004), "De Violeta Parra a Víctor Jara y Los Prisioneros: Recuperación de la memoria colectiva e identidad cultural a través de la música comprometida." Latin American Music Review / Revista de música latinoamericana 25, no. 2: 195-215. doi: https:// doi.org/10.1353/lat.2004.0022.

VILCHES Patricia (2008), "El cuerpo femenino: Efectos estéticos de la política liberal y la violencia urbana en las Décimas de Violeta Parra." Ixquic: Revista hispánica internacional de análisis y creación 8/9: 61-83.

VILCHES Patricia (2017), Blest Gana via Machiavelli and Cervantes: National Identity and Social Order in Chile. Newcastle upon Tyne, UK, Cambridge Scholars Publishing.

VIOLETA SE FUE A LOS CIELOS (2011), Dir. Andrés Wood. Actrs. Francisca Gavilán, Thomas Durand, Gabriela Aguilera, Roberto Farías, Luis Machín y Marcial Tagle. Agência Nacional do Cinema (ANCINE); Instituto Nacional de Cine y Artes Audiovisuales (INCAA)(colaboración); Maíz Producciones; Wood Producciones.

\section{NOTAS FINALES}

i. Todas las traducciones del inglés al español son mías.

ii. Por años el lugar de nacimiento de Violeta Parra ha sido disputado. Isabel Parra afirma que "pese a que suele vinculársela a San Carlos, ella misma hablaba de San Fabián como su lugar de nacimiento" (2015: p. 33). Por ejemplo, en Cantos folklóricos chilenos (1979), la primera fotografía de Violeta Parra identifica a la artista como "Nacida en San Carlos y criada en Chillán".

iii. Duarte Riascos analiza que en Violeta Parra, en su arte y su producción artística, se exhibe una conceptualización global que une su arte con ella misma, un todo que el crítico denomina 'La violeta.' (2018: p. 44).

iv. Manns (2017) afirma que las radioemisoras estaban a cargo de la oficialidad mientras que los poetas populares se encargaban de la 'otredad' noticiosa. A modo de ilustración, el autor alude al canto superficial de los Cuatro Cuartos en comparación a las narraciones por parte de los juglares chilenos sobre crisis por el salitre y escasez de alimento a nivel nacional (pp. 97-98).

v. Morales se refiere a la entusiasta recepción de las Décimas en el periodo 1970-1973 en Chile (pp. 63-64).

vi. Nicanor Parra graba su 'Defensa de Violeta Parra' en 1960 acompañado en guitarra por su hermana (Véase Recordando a Chile Odeón, 1965). Pablo de Rokha escribió sus versos en 1964.

vii. Ángel Parra meciona las preferencias de los sectores conservadores chilenos con respecto al repertorio de Violeta Parra. Véase Epple (2012), cap: “La pasión del canto” (p. 37).

\section{RESÚMENES}

El gran legado artístico de Violeta Parra se evidencia en los diferentes empeños y preocupaciones que se reflejan en sus quehaceres artísticos, entre los que se delinean las Décimas. Autobiografía en versos. La obra poética absorbe los espacios del diario vivir de la artista chilena, tomando en cuenta su niñez, juventud y adultez, en una narración que describe los avatares del chile de la modernidad a la vez que su vida por suelos extranjeros. De esta manera, este estudio analiza las 
Décimas bajo ópticas en que se destacan: una búsqueda de la innovación y reafirmación de la tradición; un diario vivir íntimo que se traduce en una narración nacional; y, espacios conflictivos, de género y de enfermedad del cuerpo y la nación.

Le grand héritage artistique de Violeta Parra est évident dans les différents efforts et préoccupations qui se reflètent dans ses activités artistiques, y compris celles qui sont délimitées dans les Décimas. Autobiografía en versos. Le travail poétique absorbe les espaces de la vie quotidienne de l'artiste chilienne, en tenant compte de son enfance, de la jeunesse et de l'âge adulte, dans un récit qui décrit les avatars du Chili de la modernité ainsi que sa vie à travers les pays étrangers. De cette manière, cette étude analyse les Décimas sous l'optique d'une recherche d'innovation et de réaffirmation de la tradition; d'une vie quotidienne intime qui se traduit par un récit national; et, des espaces de conflit, des rôles de genre et de la maladie du corps et de la nation.

\section{ÍNDICE}

Mots-clés: Violeta Parra, Décimas, espaces de conflit, maladie, nation, Chili, modernité.

Palabras claves: Violeta Parra, Décimas, espacios de conflicto, enfermedad, nación, Chile, modernidad

\section{AUTOR}

\section{PATRICIA VILCHES}

Professor of Spanish and Italian and Scholar in Residence, Harlaxton College,pvilches

(at)harlaxton.ac.uk 